\title{
Characterisation of Infant Food Modifications in the European Union
}

\author{
Berthold Koletzko ${ }^{a}$ Margaret Ashwell ${ }^{b}$ Birgit Beck ${ }^{c}$ Andrée Bronner ${ }^{d}$ \\ Basil Mathioudakise
}

${ }^{a}$ Dr. von Hauner Children's Hospital, Ludwig Maximilian University of Munich, Germany; bAshwell Associates, Ashwell, Hertfordshire, UK; ' ${ }^{A}$ sssociation for Consumer Information, VKI, Vienna, Austria; ${ }^{\mathrm{d} A s s o c i a t i o n}$ of the Food Industries for Particular Nutritional Uses of the European Union, Paris, France, and eHealth and Consumer Protection Directorate General, European Commission, European Union, Brussels, Belgium

\section{Key Words}

Clinical trials $\cdot$ Infant food $\cdot$ Postmarketing product surveillance $\cdot$ Research design. Safety

\begin{abstract}
Improvements in the understanding of human milkcomposition, in dietetic effects on physiological outcomes in infants, and in food technology have lead to modifications in infant formulas and other dietetic products for infants. In Europe, new ingredients may be added to infant formula and follow-on formulas if their suitability for particular use by infants from birth has been established by generally accepted scientific data. However, there is uncertainty as to the nature of the evaluation needed to evaluate whether modifications in dietetic products for infants can be regarded as suitable and safe. Moreover, there is no agreement on the nature of evidence required to justify the scientific validity of potential effects on infant health and well-being, which might provide the basis for the communication of such effects to
\end{abstract}

The content of this publication does not necessarily reflect the views of the European Commission and in no way anticipates the Commission's future policy in this area. health professionals and consumers. Therefore, a scientific workshop was held under the auspices of the Child Health Foundation, Munich, Germany, and the European Society for Paediatric Gastroenterology, Hepatology and Nutrition to discuss issues arising in this area among participants representing academia, infant food industry, consumer organisations, the European Commission, and food regulatory bodies of some European Union member states. This article summarises the outcomes of this workshop. The participants agreed on general concepts of evaluation of innovations and on establishing evidence for benefits, but felt that further discussion would be necessary on the principles and practicalities involved in setting up a central register of clinical trials and of a central repository of trial data.

Copyright @2002 S. Karger AG, Basel

Prior to the annual meeting of the European Society for Paediatric Gastroenterology, Hepatology and Nutrition (ESPGHAN), a scientific workshop was held on June 2-4, 2002, at Giardini Naxos, Italy, to discuss the nature of evaluation needed for innovations of infant formula and other dietetic products for infants. The workshop was jointly sponsored by the Child Health Foundation, Munich, and by ESPGHAN, and was attended by some 50

Prof. Berthold Koletzko, MD, Division of Metabolic Disease and Nutritional Medicine Dr. von Hauner Children's Hospital, Ludwig Maximilian University of Munich Lindwurmstrasse 4, D-80337 Munich (Germany)

Tel +49 8951603967 , Fax +498951603336

E-Mail bkoletz@helios.med.uni-muenchen.de
Fax + 41613061234 E-Mail karger@karger.ch www. karger.com

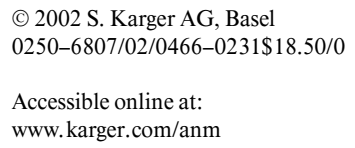


participants representing academia, infant food industry, consumer organisations, the Health and Consumer Protection Directorate General of the European Commission, and food regulatory bodies of some European Union member states. This article summarises the outcomes of the discussions.

The background and aims of the workshop were outlined by Berthold Koletzko (University of Munich). Improvements in the understanding of the chemical and nutrient composition of human milk, in the dietetic effects on physiological outcomes in the infant, and in food technology have led and continue to lead to modifications in infant formulas, follow-on formulas and other dietetic products for infants. In Europe, ingredients may be added to infant formula and follow-on formulas if their suitability for particular use by infants from birth has been established by generally accepted scientific data. However, there is uncertainty as to the nature of the evaluation that is needed to test whether modifications in breast milk substitutes and other dietetic products for infants can be regarded as suitable and safe. Therefore, the workshop should provide an open discussion of the issues arising in this area. The participants described and discussed available options for practical approaches to the evaluation of infant food products. These proposals were explored and areas of consensus defined.

Koletzko drew attention to a medical position paper from the ESPGHAN Committee on Nutrition on 'The nutritional and safety assessment of breast milk substitutes and other dietary products for infants' [1]. The key messages from this position paper are summarised in table 1 . The participants were asked to consider these statements during the workshop.

Further questions arise from accumulating scientific evidence that dietary choices in infancy exert marked effects on infant health and well-being, over and above the fulfilment of basic nutrient requirements. The European Union White Paper on Food Safety [2] states that 'Consumers have the right to expect information on food quality and constituents that is helpful and clearly presented; so that informed choices can be made'. In the context of products for particular nutritional use by infants, an important but unanswered question is what degree of evidence might be required to justify the scientific validity of potential effects on infant health and well-being, and thus might provide the basis for the communication of such effects to health professionals and/or the consumer. The following questions were highlighted for consideration.

(1) What nature of evidence is needed to characterise suitability and safety?
(2) Is a reasonable indication of a functional, clinical, and other benefit required to justify formula modification, or is documentation of reasonable safety sufficient, without indication of benefit?

(3) Which approaches might be suitable to appropriately characterise product properties that might be communicated?

\section{Aspects of the Relevant Legal Framework in Europe}

Basil Mathioudakis (Health and Consumer Protection Directorate General, European Commission, Brussels, Belgium) reported that foods intended specifically for infants and young children are considered, under European Community law, as foods for particular nutritional uses, otherwise called 'dietetic' foods. Foodstuffs for particular nutritional uses are defined in the relevant Commission Directive 89/398/EEC. Foods for particular nutritional uses must be safe and have these particular properties: (1) have a special composition; (2) be distinguishable from normal foods; (3) be suitable for fulfilling particular nutritional requirements, and (4) when marketed should indicate such suitability.

Dietetic foods intended for infants and young children in good health are regulated by specific or vertical directives which lay down: (1) the necessary definitions; (2) detailed compositional criteria, and (3) specific labelling requirements including certain conditions for claims.

The basic composition of European infant formulas has been defined in the 'Commission directive on infant formulae and follow-on formulae' [3]. Since then the inclusion of further ingredients such as nucleotides, selenium, phospholipids and long-chain fatty acids has been allowed through amendments of the directive $[4,5]$. The addition of other components, or the introduction of further modifications of infant formulas and follow-on formulas is considered possible if their suitability for particular use by infants from birth has been established by generally accepted scientific data. However, there is uncertainty as to the nature of the evaluation needed to provide scientific validity that modifications of breast milk substitutes and other dietetic products for infants can be regarded as suitable and safe. Mathioudakis also commented that European Union Member States had transposed the European Union Directive into national laws and are responsible for controls in their national territory. 
Table 1. Key points of ESPGHAN Commentary on the Nutritional and Safety Assessment of Breast Milk Substitutes and Other Dietary Products for Infants [1]

1 Although human milk composition can be a guide to that of breast milk substitutes, the comparison of outcomes with those seen in healthy infants who have been exclusively breast fed for 4-6 months is considered a better approach

2 Appropriate clinical studies of nutritional and safety assessment should be performed particularly for components, and combinations of components, which have not been previously included in infant formulas and other dietary products for infants. Technological as well as compositional modifications to infant formulas should be assessed nutritionally

3 The introduction of any modification to a formula or other dietary product for infants should be based on a systematic review of the relevant existing information to develop a clear hypothesis of the expected functional and clinical benefits. These reviews should be published or be made publicly available in other forms. Studies should be designed primarily to test these hypotheses, as well as making general nutritional assessments

4 Infant formulas or other products modified for reasons other than to provide a novel functional or clinical benefit, or which are based on products already on the market, should, at least, be subjected to studies of acceptability, and of nutritional equivalence to the existing products

5 All infants in clinical trials should be characterised with regard to factors which might affect the planned outcomes. Blind randomisation with respect to the allocation of test and reference formulas is important, and all studies should comply with Good Clinical and Good Laboratory Practices

6 For all clinical trials on nutritional products, ethical approval should be acquired, informed parental consent obtained and this should be declared in the publication of results

7 Modifications of infant formulas and other dietetic products for infants need to be evaluated for their safety. It is important that the possibility of unexpected adverse outcomes be addressed by adequate clinical monitoring of participants, and by incorporating, into the study design, arrangements for the independent scrutiny of the accumulating data

8 The general principles, design, execution and the data analysis of evaluative studies of infant formulas and other substitutes for breast milk need to be determined to detect relevant short- and long-term (i.e. in later childhood and adult life) outcomes. The design should consider from the outset the statistical power of the study, and the confidence limits of any differences found should be included in the published reports

9 Preliminary pilot studies of the proposed study design are often useful to identify and anticipate outcomes and issues which would inform definitive studies and enable protocols to be adapted and would enable the views of the infants' carers to be taken into account. This approach would be expected to enhance the co-operation of carers and the quality of the methodology of the subsequent definitive assessment

10 Manufacturers and scientific, academic, and professional groups should collaborate to the extent of agreeing on an essential portfolio of data and outcomes, which should be recorded in all nutritional studies performed during early life. This would enable the later consolidation of information from individual studies into larger databases which would be appropriate for the assessment of long-term nutritional efficacy and safety, as well as being able to detect unanticipated outcomes of early feeding practices and dietary exposure

11 A register of current trials of infant formulas should be established, and wherever possible, this information should be accessible to manufacturers and to clinical researchers. It should be used to reduce overlap between investigations, should avoid unnecessary replication of studies, and encourage collaborative projects particularly in the evaluation of pre-competitive modifications. Similar collaborations would facilitate the creation of cohorts, which should be large enough to enable follow-up of the studied infants through their childhood and into adulthood. It was considered possible to achieve this without compromising intellectual property rights, commercial confidentiality and competition between manufacturers

12 Original study records, with protection of the participants' confidentiality, should be preserved wherever possible; from these an anonymous data archive could be made publicly available for retrospective epidemiological assessment of associations with adverse and beneficial outcomes

13 The results of studies and nutritional trials in infants that have not been completed or have not been published for other reasons should at least be made available publicly, and to the consolidated database, together with the specific reasons for the cessation of the study. Similarly, the specific reasons why children withdrew from completed studies should be included in the published reports 


\section{Innovation and Its Implementation: Vision and Reality}

Elaine Underwood (Wyeth, UK) outlined the three routes that have been identified for innovation of infant formula in the EU, as follows.

(1) The ability to add food ingredients whose suitability for particular nutritional use by infants from birth has been established by generally accepted scientific data [3]. There is a similar provision for follow-on formulae given to infants over 4 months of age who consume a diverse diet.

(2) The innovation clause in the Directive on the Foodstuffs Intended for Particular Nutritional Uses [6].

(3) Amendments to the EC Directive on Infant and Follow-On Formula [4, 5].

Compliance is also required to meet the various horizontal regulations, for example, the Novel Foods Legislation and Additives Directives, should the innovation require a change to those permitted, and Guidance Documents of the Scientific Committee on Food [7, 8]. Of these three routes, industry found only that the first route was able to meet the important and practical criteria of making changes within an acceptable and quantifiable time period, retaining confidentiality for the company introducing the innovation, as well as ensuring the safety of the infant. The latter is implicit in the wording of the article. This innovation does, however, only apply to new food ingredients, while other types of innovations would have to follow one of the alternative routes.

Underwood gave her future vision of innovation, as follows. Any directive or legislation implemented within the EU should continue to permit innovation, when the suitability of an ingredient for particular nutritional use has been established by generally accepted scientific data, as is detailed in the current Infant and Follow-On Formula Directive. There also needs to be an established route for innovation other than for the addition of a food ingredient. The establishment of the above must be able to pass on benefits both for infants born in the next few years and make provision for those born in the next decade and beyond. Thus the innovation framework must include a timely introduction to ensure that infants are able to benefit from modern scientific knowledge, bearing in mind that nutrition in the first months of life can set a precedence for health for many years beyond. The retention of confidentiality for the manufacturers to launch the product innovation is required to compensate for the heavy financial cost of development, and manufacturers should be able to communicate the innovation. Underwood be- lieved that these points are essential in order to innovate formulas to the benefit of today's infant and fund further developments for those born in the future.

Participants wondered if the inability to make claims reduced the funds which were spent on clinical research. Underwood considered this true to a certain extent. But ideally industry would like to work more within a legal framework rather than a creative one, largely led by marketing departments. Industry representatives expressed concerns about the confidentiality of submissions through scientific advisory systems and were assured that the authorities did everything they could to maintain confidentiality because they would prefer companies to take the legal rather than the creative route. Creativity with indirect claims tends to lead to consumer confusion, therefore clear legal guidance would reduce this too.

\section{Evaluation of Infant Foods: Consumers' Expectations}

Concerning the nutritional and safety assessment of breast milk substitutes and other dietetic products for infants, Birgit Beck (Association for Consumer Information, VKI, Vienna, Austria) stressed that VKI supports the recommendations given by the ESPGHAN Committee on Nutrition [1]. For consumers it is crucial that there is a systematic evaluation of breast milk substitutes and other dietetic products for infants for long- and short-term outcomes and that this is overseen and evaluated by independent scientific committees in a transparent way. From a consumer point of view dietetic products for infants must be clearly and understandable labelled, all communication must be truthful and science-based, and misleading labelling and advertising must be avoided. The participants agreed that it is important for industry to comply with spirit as well as letter of law and that food safety and public health interests must take priority over the economic interests of the food industry.

\section{Pre-Clinical Evaluation of Safety and Nutritional Adequacy of Infant Formulae and Follow-On Formulae}

Marie-Christine Secretin (Nestec Ltd., Vevey, Switzerland) reviewed the tools available for manufacturers to describe the safety and nutritional value of infant formulas subdivided into those used for proteins, fats, carbohydrates, minerals, vitamins and selected other nutrients. 
Secretin then outlined the following practical suggestions for pre-clinical assessment of nutritional value of a new infant formula, recognising that the extent of the assessment can be determined only on a case-by-case basis.

The description of the innovation should include: the rationale for the proposed modification; a description of the proposed innovation and of new ingredient(s); the way of addition; a description of the technological process applied to the formula with particular emphasis on the dry mixing vs. wet mixing steps, and a review of the literature and other information available in the area of the proposed innovation (table 1, point 3). When innovation involves a change in protein source, or any technological process that may affect protein quality, pre-clinical assessment should include not only the amino acid profile, but also a relevant measurement of amino acid availability (for instance lysine blockage and protein efficiency). When innovation is limited to the use of a new ingredient, added by dry mixing, for which no interference with other formula ingredients is to be expected, pre-clinical assessment may be limited to the ingredient itself. The guidance of the Scientific Committee on Food for safety evaluation of nutrients [7] should be used as a guide although it might not be fully applicable in each case. Moreover, in case the nutrient is not a pure chemical compound, but a natural extract rich in the desired nutrient, particular attention should be given to possible allergenic residues from the original source. When innovation includes the addition of a new ingredient submitted to further technological processing, the potential effects on the ingredient and other components of the formula should be described, as guided by manufacturer's scientific awareness and possible effects described in the literature review. Corresponding in vitro or in vivo determinations in animal models should be conducted, when possible. In all cases where innovation falls under the definition of a novel food, the Novel Foods procedure as described in the corresponding European Regulations should apply.

During the discussion participants agreed with Secretin's points and emphasised the importance of basing the introduction of any modification to a formula on a systematic review of relevant existing information (table 1, point 3). Representatives from regulatory authorities agreed that industry should provide products which are not just safe but which also meet nutrition requirements. In their quest for innovation, companies must not forget about the general nutritional profile of the entire product.

\section{Evaluation of Infant Growth}

Kim F. Michaelsen (Royal Veterinary and Agricultural University, Copenhagen, Denmark) reviewed the factors regulating infant growth and made the following recommendations. Any study on growth performed for evaluation of new or modified nutritional products for infants should as a minimum include the following growth parameters: weight, length and head circumference. Furthermore, it would be desirable to include a measure of body composition, such as skinfolds and arm circumference, but this should be considered optional in view of uncertainties as to the accuracy and precision of simple markers of body composition. The participants agreed with these suggestions and also that these measurements should be made monthly. The duration of the study should be at least 3 months. The participants agreed that a 3-month study on infant formula should preferably start from birth, although they recognised the practical difficulties that this might cause. As a minimum, the study should have a power to detect a difference in weight gain equal to $0.5 \mathrm{SD}$. The participants agreed, although some concern was expressed that the number of infants needed in a study had direct consequences on the costs involved. Others mentioned that multi-centre trials would be needed and that measurement methods of outcomes would require standardisation in the different centres. Participants agreed that the study outline should generally allow potential follow-up later in childhood in order to evaluate possible long-term effects. It was also agreed that studies should be designed such that they could be included in larger databases with the purpose of allowing meta-analysis with a higher power and more detailed evaluation of how different dietary components influence growth. The workshop participants further agreed on the need to register some marker of infant formula intake, even if only rough methods such as using bottles with demarcations to show the amount drunk were available. Ideally all studies should include a breast-fed reference group for comparison (table 1, point 1), but reference data for growth of comparable populations of breast-fed infants may substitute for this.

The participants discussed what change in an infant formula would demand a growth study. They agreed this was needed when there were changes in energy density beyond established limits, significant changes in macronutrient composition, new or markedly modified nitrogen sources, concerns about the bioavailability of macronutrients, or any other concern that growth could be altered. 
Michaelson indicated some future directions for evaluating infant growth and the workshop participants agreed that these were relevant. Accurate and precise methods for measuring body composition which are easy to use in large studies should be developed. Appropriate biochemical indicators which can describe the mechanisms through which nutrition regulates growth (e.g. IGF-1 and insulin) should be identified. The use of such indicators might allow short-term estimation of how a nutritional product will influence growth, without having to wait for a significant growth effect to develop.

\section{Investigation of Nutrient Bioavailability}

Jacques Rigo (University of Liège, Belgium) explained that nutrient bioavailability techniques are needed to evaluate the efficacy and safety of nutritional products for pre-term and term infants. When innovation involves the use of a new ingredient or a change in nutrient sources or in technical processes that may affect and interact with nutrient quality and efficiency, careful evaluation of the nutritional adequacy assessment should be obtained, as recommended by various expert committees [1,9-11]. Several techniques have been developed to assess the absorption, retention and metabolic fate of various nutrients, including balance studies, use of stable isotope tracer methodology, and dual X-ray absorptiometry. The more appropriate technique needs to be selected on a case-by-case basis according to a systematic review of relevant, existing information on the technical as well as compositional innovations concerned in the infant formulas. The workshop participants generally agreed with the views expressed in this paper.

\section{Evaluation of Biological and Clinical Outcomes}

The main point made by Alan Lucas (University College, London, UK) was that there is increasing interest in the biological effects that nutrition has on long-term health. This is in contrast to focusing only on meeting nutritional needs, preventing specific nutritional deficiencies and excesses, and on nutrient handling. This level of nutritional interest should be reflected in the way new infant formulas are evaluated. Current evaluation generally comprises effects on short-term nutritional status (notably growth, nutrient balance and biochemical response) together with measures of gastrointestinal tolerance. However, trials conducted by Lucas in infant nu- trition over the past 20 years have demonstrated that: (1) nutrition may have a major impact on long-term efficacy and safety outcomes, some of which were not previously suspected using cruder methodological approaches, and (2) 'nutritional programming' occurs in humans: early nutrition during relatively brief time periods can have major long-term programming effects on cardiovascular risk factors, bone health, immune responses and neurocognitive function.

Lucas presented recommendations for outcome testing of infant formulas. Since infant nutrition, including formula design, can impact on health outcomes, it is no longer satisfactory to assess novel infant formulas solely in terms of their impact on nutritional status, growth and tolerance; appropriate health outcomes need to be included, if not given precedence. These may include at least medium-term effects on cognition, atopy, infection, cardiovascular risk factors, bone health, etc., according to the plausible hypotheses being tested. 'Regular' infant formulas, with uncontroversial composition, have generally not been subjected to medium- or long-term outcome efficacy and safety testing. Given the emerging data, it would seem sensible, even if not mandatory, for opportunities to be sought to identify which formula designs, optimise outcome (comparing formulas with each other and with breast-fed reference populations). Since formal clinical efficacy and safety trials have proved sensitive in detecting small but important differences (in population terms) between groups, it would seem that this methodology should be the norm. Because of the many pitfalls of clinical trial design and of trial data analysis, some standardisation of approach is important and would permit cross comparison and meta-analyses of trials. It is now clear that we must at least begin to grapple with the issue of long-term efficacy and safety effects, despite the financial, organisational and practical difficulties. The United States Food and Drug Administration (FDA) is now interested in getting commitment from some US companies to undertake 'post-marketing surveillance' (PMS). This concept is valid in a pharmaceutical setting, where 'rare events' that may result from use of a new drug are likely to be identified from reports to the company. However, if a child, from a nutritional intervention study, has an IQ of 106 rather than a potential of, say, 112, or a diastolic blood pressure of $76 \mathrm{~mm} \mathrm{Hg}$ rather than say, 70, this would never be identified as an adverse event in any PMS screening. Clearly, subtle, but important shifts within the Gaussian distribution can only be detected by sensitive techniques. Lucas proposed that any new trial on infant formulas should be set up in such a way that later follow- 
ups of the original trial cohort are feasible. The two important elements in this regard are: (1) seeking permission from the subjects at the outset to take part in a longitudinal study (and obtaining appropriate ethical permission), and (2) calculating sample size to enable later outcome testing in the face of inevitable long-term cohort attrition.

The workshop participants agreed with Lucas that the long-term implications of feeding infant formulas must be considered, but voiced concerns over the practicalities of such investigations. Lucas said he was not suggesting that we should ignore the short-term aspects of infant formulas or wait for long-term data until an infant formula is marketed. Rather, we must set up current randomised controlled trials (RCTs) of infant formulas in such a way that, in the future, we can base recommendations on functional outcome data. Some of the participants suggested that evaluation of the long-term effects of infant feeding would in many cases need to be supported by public research funding. Workshop participants also pointed out that if we need to know what is best for children in Europe we need to do studies in the EU, and cannot always base our conclusions on studies performed in populations living under very different dietary and other conditions. We must further build a proper collaboration infrastructure for trials in Europe, and it is recognised that the EU's Sixth Framework Programme offers possibilities here.

\section{Clinical Trials: General Considerations}

There is increasing emphasis on the need to practice evidence-based medicine and the strongest evidence comes from well-designed and well-conducted RCTs. Ruth Morley (University of Melbourne, Department of Paediatrics) emphasised that trials can be designed to detect either a difference between diet groups (comparative trials) or equivalence in terms of the main effect. Issues relating to comparative trials are outlined here, and then the differences between comparative and equivalence trials are highlighted. Morley covered different aspects of study design and management (table 1, points 5-9) before giving advice on statistical analysis, including defining the primary and secondary hypotheses, pilot studies, randomisation, sample size, trial monitoring, masking (blinding), subject attrition and non-compliance, and collecting the right data. She concluded that much thought, effort and resources are required to carry out an effective comparative or equivalence trial. Advice from biostatisticians and/or epidemiologists, or from re- searchers with experience in clinical trials methodology and following up cohorts of children, will help to ensure successful completion of worthwhile trials. Trials should follow the principals of good clinical and laboratory practice.

The participants agreed with all points Morley had made. They agreed that pilot studies should be used to anticipate likely dropout rates and that it was impossible to predict what level of dropout was acceptable. The importance of collecting good data on the reference group was stressed to avoid bias if it was impossible to select this group to match those in the study groups for, say, social class. The importance of the heterogeneity of subjects involved in public health studies of infant formulas must be recognised since the products will be used world-wide in populations with a very wide range of characteristics. Calculation of sample size should take the heterogeneity of the population into account; multi-centre trials contain intrinsic heterogeneity. The participants accepted that sometimes it is impossible to perform a double-blind $\mathrm{RCT}$, for example if the properties of a dietetic product could not be fully blinded. In these cases, at least the study personnel involved in assessing and evaluating outcomes should be blinded as far as possible, but possible limitations of this type of data will have to be accepted. All data are valuable but there is a data hierarchy on which decisions are made, with the double-blind RCT at the top of this hierarchy.

The set of core data proposed in the draft ESPGHAN Medical position paper on Core Data on Nutrition Trials in Infants was discussed and participants agreed, on the whole, that these are valuable recommendations. They suggested that further identification data should be added about the parents of the infant, particularly that relating to smoking habits. They felt that the feeding history should include the general type and duration of formula feeding to match the extent of questions about breastfeeding.

\section{Should All Clinical Trials Be Registered and Core Data Submitted to a Central Data Repository?}

Peter Aggett (University of Central Lancashire, UK) addressed points 10-12 (table 1) of the ESPGHAN Committee on Nutrition Medical Position paper relating to a possible central register of trials and a central data repository. He summarised the following benefits of such a scheme: (1) it could be useful, but still set up to protect 
confidential and commercially sensitive information and data; (2) it could facilitate collection of pooled data for generic interventions, for reference from breast-fed infants and multi-centre studies (in doing this it would provide a means of achieving best practice in research methodology and study design, and would foster benchmarks for practice and continuing improvements in conduct of research), and (3) a register could monitor studies for adverse effects, avoid unnecessary replication of studies or alternatively provide harmonised templates for databases. It would give the ability to consider data from abandoned studies. Other roles which a registry could serve are those of providing a means for the independent and complete ethical review of research proposals, and of providing an interface with a competent regulatory authority, the evidence that would be required to meet the product manufacturer's case for product approval.

Aggett pointed out that, to work well, there would be a need for willing collaboration between the food industry and regulatory authorities, clinical researchers, and consumers, and agreement on key objectives and their implementation. Because of the vast potential for conflict of interest, the Registry and Repository should operate separately and independent of each other. Perhaps the former should be associated with a central authority at the EU level. Aggett concluded that a central registry, operating say at a European level, for clinical trials, and a repository for data from completed and uncompleted trials would enable high-quality ethical research using harmonised core protocols which would underpin cost-effective use of multi-centre resource both for initial clinical trials and also, through the aggregation of data from several studies, for long-term follow-up of benefits and safety.

During the discussion of Aggett's paper, it was obvious that some of the participants had reservations about the implications of points 10-12 in the ESPGHAN Committee on Nutrition Medical Position paper (table 1). The main concerns related to human rights and data protection issues, and it was pointed out that the objectives, expected achievements and benefits for the participating industries would need to be more clearly defined. Questions also arose as to the rights on the data entered and their exploitation. Other participants thought Aggett's suggestion offered many advantages and would be happy to co-operate because they predicted that such a register would help to earn the trust of the public. A central register for infant formula trials could be trailblazer for all trials on foods. Two types of data repository might be needed. One which gives co-ownership of data for pan-EU collaboration and one which gives data to a third party for perpetuity. The participants saw more problems with the latter than the former. In summary, the participants agreed to the general principle proposed in Aggett's paper, but were divided as to whether the practical difficulties were insuperable or not.

\section{Specific Considerations in the Evaluation of Follow-On Formulae and Complementary Food Products}

Carlo Agostoni (University of Milan, Italy) argued that a relatively similar dietary pattern for the 6- to 12 -month period seems to be emerging among the various European countries, that is, an early trend towards diets high in proteins and poor in soluble fibre, polyunsaturated fatty acids and selected micronutrients, such as iron and zinc. $\mathrm{He}$ believed that one of the main reasons for this trend lies in the switch from human milk or formula feeding to whole cow's milk already during the first year of life. The weaning period is acquiring a new identity as a possible critical period for the role of nutrients in the programming of later health. These findings have practical implications for the evaluation of new complementary products. Attention should be reserved for the functional effects of diets, in order to ensure the most physiological development of all organs and tissues according to the individual characteristics of the complementary feeding period. Pre-clinical testing with in vitro and in vivo evaluation should be considered for complementary feeding products.

During the discussion of Agostoni's paper, the participants agreed that we definitely need more information on nutrition during months 6-12 of an infant's life and that randomised controlled trials should and can be performed at this age to evaluate feeding concepts and major modifications of follow-on formulae. However, a number of participants felt that most modifications of complementary feeding products, which contribute only a minor part to an infant's dietary in take, would not justify the large effort and expense of a randomised controlled trial.

\section{Characterisation and Communication of Product Properties and Benefits}

Berthold Koletzko (University of Munich) indicated that under current EU legislation, manufacturers of infant formula may communicate some aspects of nutrient composition by defined claims (e.g. iron enriched). In addition, the property 'hypoallergenic' may be communicated 
if a protein hydrolysate, meeting a certain specification, is used. However, scientific data increasingly show that feeding dietary choices in infancy exert additional effects on infant health and well-being over and above the fulfilment of basic nutrient requirements. Thus, an important question is how such properties of dietetic products might be communicated to health care professionals, and potentially to the consumer, and which degree of scientific evidence might be required to justify the validity of such potential effects on infant health and well-being. Koletzko proposed that in addition to a description of nutrient content, the description of functional outcomes (e.g. softens stools) and of effects on health or reduction of disease risk (e.g. reduces diarrhoea risk) should be considered.

In the ensuing discussion, dissatisfaction with the current legislation on claims from the point of view of consumer organisations was voiced. The need for a clearer and more detailed communication of product properties and effects was emphasised, including communication of functional and health effects. Consumer organisations expect that all communication is truthful, based on valid scientific data, and is overseen by independent scientific experts, and they suggest that similar principles should apply to all dietetic products used for infants, including infant formulae, follow-on formulae, weaning foods, and foods for special medical purposes used in infants. Other participants stressed the need that the establishment of any functional or health effect of a specific product would generally need to be based on at least two different and independent clinical trials.

\section{Post-Marketing Surveillance}

Each year several million infants in Europe are fed infant formulas and commercially prepared weaning foods and, in the large majority of instances, both parents and infants are completely satisfied with these products, said John Wells (Royal Numico, Trowbridge, UK). He thought that, during the past more than 25 years, the infant food industry has had a remarkably good safety record. Two examples of PMS schemes in USA and UK, set up for the pharmaceutical industry, were compared. The Special Nutritionals Adverse Event Monitoring System administered by the US Food and Drug Administration and the Yellow Card Scheme co-ordinated by the UK Medicines Control Agency are schemes that monitor the safety of nutritional products and drugs respectively. These two examples have three important differences, namely which products are included, who can report problems with the products, and the independent assessment of adverse effects before they are made public. Since the monitoring scheme for food that is likely to be adopted in Europe will have many differences to the scheme for PMS currently used in the pharmaceutical industry, Wells proposed the alternative name 'in-market product performance review' and drew the following differences in approach: PMS is the monitoring of adverse responses and/or events by medical doctors or similar professionals resulting from the use of pharmaceutical products by sick individuals who are under the care of a medical doctor. An 'in-market product performance review', however, is the monitoring of adverse responses by consumers, doctors and other health care professionals resulting from the use of a new infant formula or a significantly changed infant food used by healthy infants who are cared for by their mothers.

The collection of PMS data by food companies may be seen as an activity which contributes towards fulfilling existing obligations to provide safe food under current food law. The principle that food companies take responsibility for the safety of their products is also embodied in a new EU regulation that becomes effective in January 2005. This requires companies to notify the relevant competent authorities if they have reason to believe that any of their products may be injurious to health.

The setting up of in-market product performance review' will inevitably raise a number of questions. Which products should be included in the scheme? Who can report adverse reactions? What information is required? Where can reporting forms be obtained? Who will be responsible for collating and interpreting the reports? Who will be responsible for taking any necessary action in light of the reports? Should the reports be made directly available to the public? How would malicious/false reporting be detected and dealt with? Should the scheme have a statutory basis? What are the roles of industry/ health care professionals/government? How will the scheme be funded?

In April 2002 Numico initiated a pilot trial in the UK and Belgium for collecting and evaluating in-market product performance data on infant formulas. Wells presented the first results from this trial to the participants at the Workshop which confirmed that this approach is practical, efficient and is sufficiently sensitive to detect minor changes in products. Wells concluded that all post-marketing schemes have their limitations and at best they provide a crude 'first alert' that warrants further investigation. The instruments established for recording PMS will record many factors and it is difficult to establish causality. 
Roberto Moran (Mead Johnson, Evansville, Ind., USA) has participated in a panel set up by FDA to develop guidelines for testing infant formulas within the next 2 years. Two workshops have been held, and a decision tree, guiding principles and a guide to clinical study execution have been developed. A PMS scheme is demanded by the Infant Formula Act in USA and manufacturers must maintain records by law. Like Wells, Moran prefers to call this 'in-market assessment'. Again, adverse event reporting can show fluctuations, and increases can relate to trivial changes unrelated to the infant formula such as a change in the colour of label, and it allows the manufacturer to follow trends in complaints. These are reviewed by an independent expert advisory panel. In response to questions from participants, Moran confirmed that his company has considered a comprehensive post-marketing assessment system essential, not just to obey the law but to help with consumers' questions and better understand consumers' needs.

The participants agreed that passive surveillance schemes which relied on input from consumers could only provide early signals of adverse effects. These were often spurious and could relate to changes in product labelling or product appearance. One would need a structured, proactive way of collecting data on adverse events rather than relying on a passive spontaneous method. Some participants would like to see active post-marketing schemes to detect longer term, physiological effects, for example by revisiting cohorts of infants used in the pre-market clinical studies. Concerns were, however, expressed about this idea because clinical trials are not powered to detect rare events. There was general agreement that further exploration of the potential and limitations of PMS strategies is required.

\section{Concepts of Infant Formula and Infant Food Evaluation in Other Parts of the World}

Bill Heird (Children's Nutrition Research Center, Baylor College of Medicine, Houston, Tex., USA) reviewed relevant USA legislation on infant formulas, namely the Infant Formula Act of 1983 and its amendment in 1986. These make manufacturers of infant formulas responsible for assuring the safety of marketed products. The act does not provide for pre-marketing approval of a new or modified formula by the FDA. However, manufacturers must inform the FDA of their intention to market a new or modified formula 90 days in advance of such marketing. This notification must include the reasons for assuming the formula to be marketed is safe, including a description of the studies performed to support the assumption of safety.

The act specifies that 'functional factors' will be assured. However, these factors were not identified and clinical studies were not necessarily envisioned; rather, it was assumed that the requirement for nutrient contents of formulas to be within the specified range would assure 'normal growth and development'. In 1988, the FDA contracted with the American Academy of Pediatrics Committee on Nutrition to provide advice concerning the circumstances under which clinical testing of formulas was indicated and to specify the types of clinical testing necessary to assure that the formula would support normal growth and development. This document focused on the necessity of a clinical growth study to provide this evidence and specified the type of growth study required (i.e., at least 4 months starting shortly after birth and including enough infants to detect a difference of $3 \mathrm{~g}$ /day in rate of weight gain). While this document was purely advisory, the guidelines provided by it for assuring the safety of new and/or modified infant formulas appears to have been widely accepted by both the FDA and manufacturers of infant formulas. In 1996, the FDA proposed rule changes which, essentially, would incorporate the 1998 recommendations for assuring the safety of infant formulas. To date, however, these rules have not been formalised.

Currently, neither the United States nor Canada has an established mechanism for monitoring the long-term safety and/or efficacy of infant formulas or foods containing 'novel bioactive ingredients'. Recently, the FDA, in response to a notification submitted by a manufacturer of 'novel bioactive ingredients' that these ingredients were 'generally recognised as safe' when added to infant formulas, responded that there was no basis on which to object but added that evaluation of a food ingredient as safe "is a time-dependent judgement'. Thus, FDA 'expected' any manufacturer adding these ingredients to infant formula to sponsor 'scientific studies' and to pursue 'rigorous' PMS and monitoring of formulas containing these ingredients. Although all infant formula manufacturers maintain PMS systems, these obviously are not as extensive as intended. Thus, there is considerable uncertainty about this issue, in general, and, specifically, about how to implement an effective monitoring programme of the type envisioned by the FDA. Clearly, this is not a simple issue and, at this time, no clear resolution is in sight.

Igor Kon (Institute of Nutrition, Russian Academy of Medical Sciences, Moscow, Russia) reviewed the state 
Table 2. Hypothetical examples of proposed innovations of infant formula, their potential benefits, and suggestions of workshop participants on the nature of evaluation required

\begin{tabular}{lll}
\hline Proposed innovation & $\begin{array}{l}\text { Benefits proposed by } \\
\text { product development group }\end{array}$ & Participants' suggestions for studies \\
\hline New vitamin A ester & Technological & $\begin{array}{l}\text { Stable isotope study to check bioavailability in infants, probably } \\
\text { no growth or long-term safety study needed }\end{array}$ \\
\hline New organic calcium compound & $\begin{array}{l}\text { Better calcium absorption and } \\
\text { bone mineralisation }\end{array}$ & $\begin{array}{l}\text { Bioavailability study to check absorption of calcium; growth } \\
\text { study and clinical trial on bone mineralisation }\end{array}$ \\
\hline $\begin{array}{l}\text { New and improved cows' milk } \\
\text { protein hydrolysate }\end{array}$ & $\begin{array}{l}\text { Better allergy prevention, } \\
\text { gastrointestinal tolerance }\end{array}$ & $\begin{array}{l}\text { Growth and bioavailability study needed to check adequacy of } \\
\text { protein source and safety, longer follow-up for demonstration of } \\
\text { allergy prevention }\end{array}$ \\
\hline $\begin{array}{l}\text { Palermo Pea Protein } \\
\text { Five Fibre Feature }\end{array}$ & $\begin{array}{l}\text { No risk of transmissible spongi- } \\
\text { form encephalopathy, no phyto- } \\
\text { oestrogens, cheap, patentable }\end{array}$ & $\begin{array}{l}\text { Novel component in infant formulas needs to be assessed for } \\
\text { safety, growth study required; demonstration of non-oestrogenic } \\
\text { receptor effects }\end{array}$ \\
\hline $\begin{array}{l}\text { Prebiotic, prevents constipation, } \\
\text { patentable }\end{array}$ & $\begin{array}{l}\text { Growth studies and nutrient bioavailability studies needed to } \\
\text { assess safety (equivalence study rather than comparative trial); } \\
\text { bacteriological study for efficacy }\end{array}$ \\
\hline $\begin{array}{l}\text { Bio Bacteria Brew } \\
\text { Recombinant human milk peptide } \\
\text { fropatocyte cultures) }\end{array}$ & $\begin{array}{l}\text { Probiotic, stimulates immunity, } \\
\text { prevents allergy, patentable } \\
\text { death, patentable }\end{array}$ & $\begin{array}{l}\text { Growth studies needed to check safety (equivalence study rather } \\
\text { than comparative trial); bacteriological studies and studies on } \\
\text { immune effects for efficacy }\end{array}$ \\
\hline
\end{tabular}

system of baby food sanitary expertise in Russia. Dominique Turck (University of Lille, France) reviewed the guidelines of the French Agency for Food Safety for the submission of dossiers to the Human Nutrition Expert Committee, which applies to all foods including infant formulas.

From these papers and the general discussion which ensued, the participants concluded that there were similarities in the state of legislation for infant formulas across the world. The legal requirement is for infant formulas to be safe with minimal emphasis on efficacy.

The chairman of the workshop had asked speakers to propose practical approaches for the scientific evaluation of infant food, with respect to their particular topic, and to highlight open questions and areas of controversy. In response to this request, Jacques Bindels (Numico, Belgium) led the participants in a discussion about some hypothetical examples of innovation in infant formulas provided by the chairman. Table 2 indicates the participants suggestions for the general nature of evaluation considered necessary for these hypothetical innovations. Al- though participants found it relatively easy to agree on what needed to be done for each hypothetical product, during this discussion it became obvious that any innovation would have to be evaluated on a case-by-case basis, considering a detailed review of the available knowledge and a full dossier on pre-clinical evaluation. Thus any guidance notes that eventually might be developed would have to recognise this and be couched in very general terms.

During the final discussion the chair of the workshop, Berthold Koletzko, reminded the participants of the 13 points in the ESPGHAN Committee on Nutrition Medical Position paper (table 1) and asked them whether they supported these. There was agreement with the general concept of each of the points, apart from points 10-13 where participants concluded that further discussion would be necessary on the principles, benefits and risks, and practicalities involved in setting up a central register and repository of information. 


\section{Acknowledgements}

The workshop was sponsored by the charitable Child Health Foundation, Munich, Germany (www.kindergesundheit.de) and the European Society of Paediatric Gastroenterology and Nutrition (ESPGHAN, www.espghan.org) and funded by an unrestricted grant kindly provided by the International Association of Infant Food Manufactures, Paris, France, and by participants' registration fees.

\section{Delegates Invited to the Workshop}

Prof. Peter Aggett, University of Central Lancashire, UK; Dr. Carlo Agostoni, Department of Pediatrics, University of Milan, Italy; Dr. Margaret Ashwell, Ashwell Associates, UK; Dr. Irene Axelsson, Department of Pediatrics, Lund University, Sweden; Birgit Beck, Consumers Information Association, Vienna, Austria; Lise Berg Kildemark, International Nutrition Company Ltd. A/S, Copenhagen, Denmark; Dr. Christien van Beusekom, Friesland Nutrition, The Netherlands, Prof. Jacques Bindels, Nutricia, Belgium; Dr. Heinz Michael Böckler, Numico Infant Nutrition Group, Friedrichsdorf, Germany; Dr. Günther Boehm, Numico Research Group, Friedrichsdorf, Germany; Dr. Christian P. Braegger, University of Zürich, Switzerland; Dr. Andrée Bronner, International Association of Infant Food Manufactures, Paris, France; Prof Cristina Campoy, University of Granada, Spain; Dr. Tamás Decsi, University of Pécs, Hungary; Dr. Hans Demmelmair, University of Munich, Germany; Efi Farmakalidis, Mead Johnson, Bangkaew, Thailand; Marie-Odile Gailing, Nestlé, Marne-la-Vallee, France; Prof. Jacques Ghisolfi, University of Toulouse, France; Dr. Bill Goldman, Wyeth Nutrition, St. Davids, Pa., USA; Helen Grue, International Nutrition Company Ltd. A/S, Copenhagen, Denmark; Prof. Antonio Guerra, University of Porto, Portugal; Lucia Guidarelli, Ministry of Health, Rome, Italy; Prof. Ferdinand Haschke, Nestlé Alete GmbH, Munich, Germany,
Prof. William C. Heird, Childrens Nutrition Research Center, Baylor College of Medicine, Houston, Tex., USA; Prof. Olle Hernell, Umea University, Sweden; Dr. Björn Hoffmann, University of Munich, Germany; Prof. Alan A. Jackson, University of Southampton, UK; Prof. Berthold Koletzko, University of Munich, Germany; Prof. Igor Kon, Institute of Nutrition, Russian Academy of Medical Sciences, Moscow, Russia; Prof. Harry N. Lafeber, Vrije University, Amsterdam, The Netherlands; Helen Lee, European Commission, Health and Consumer Protection Directorate General, Brussels, Belgium; Diane Loiselle, Abbott Laboratories, Abbott Park. Ill., USA; Prof. Alan Lucas, University College of London, UK; Dr. Marc Masor, Ross Products Division, Abbott Laboratories, Columbus, Ohio, USA; Basil Mathioudakis, European Commission, Health and Consumer Protection Directorate General, Brussels, Belgium; Prof. Kim F. Michaelsen, Royal Veterinary and Agricultural University, Frederiksberg, Denmark; Dr. J. Roberto Moran, Mead Johnson Nutritionals, Evansville, Ind., USA; Dr. Ruth Morley, University of Melbourne, Australia; Iwonna Niegowska, Alima-Gerber SA, Novartis Consumer Health, Poland; Prof. Hildegard Przyrembel, Bundesinstitut für gesundheitlichen Verbraucherschutz und Veterinärmedizin, Berlin, Germany; Prof. Jacques Rigo, University of Liège, Belgium; Dr. Pilar Rodríguez Iglesias, European Commission, Health and Consumer Protection Directorate, Secretariat to the Scientific Committee on Food, Brussels, Belgium; Dr. Jaap Schrijver, Royal Numico NV, Zoetermeer, The Netherlands; Dr. Wolfgang Schubert, Humana GmbH, Herford, Germany; Marie-Christine Secretin, Nestlé SA, Vevey, Switzerland; Dr. Helene Steinhausen-Kibler, Hipp, Pfaffenhofen, Germany; Catharina Tennefors, Semper AB, Stockholm, Sweden; Marco Trezzi, Plada Nord Srl - H.J. Heinz Ltd, Milan, Italy; Prof. Dominique Turck, University of Lille, France; Elaine Underwood, Wyeth, Berkshire, UK; Prof. Yvan Vandenplas, Vrije University, Brussels, Belgium; John Wells, Numico Infant Nutrition Group, Trowbridge, UK; Prof. Karl Zwiauer, Department of Pediatrics, St. Pölten, Austria.

\section{References}

1 Aggett PJ, Agostini C, Goulet O, Hernell O, Koletzko B, Lafeber HL, Michaelsen KF, Rigo $\mathrm{J}$, Weaver LT: The nutritional and safety assessment of breast milk substitutes and other dietary products for infants: A commentary by the ESPGHAN Committee on Nutrition. J Pediatr Gastroenterol Nutr 2001;32:256-258

2 Commission of the European Communities: White Paper on Food Safety. Brussels, COM, 1999.

3 Commission Directive of May 14, 1991, on infant formulae and follow-on formulae (91/ 321/EEC): OJEC L 175, 4.7.1991.

4 Commission Directives 96/4/EC of February 16, 1996, amending Directive 91/321/EEC on infant formulae and follow-on formulae: OJEC L 49, 28.02.1996.
5 Commission Directives 1999/50/EC of May 25, 1999, amending Directive 91/321/EEC on infant formulae and follow-on formulae: OJEC L 139, 02.06.1999.

6 Council Directive of May 3,1989, on approximation of the laws of the Member States relating to foodstuffs intended for particular nutritional uses (89/398/EEC): z, L 186, 30.6.1989, p 27.

7 Scientific Committee on Food, European Commission: Guidance on submissions for safety evaluation of sources of nutrients or of other ingredients proposed for use in the manufacture of foods. Opinion expressed on July 11, 2001. SCF/CS/ADD/NVT 21 Final, July 12, 2001.
8 Scientific Committee on Food, European Commission: Guidance on submissions for food additive evaluations by the Scientific Committee on Food. Opinion expressed on July 11, 2001. SCF/CS/ADD/GEN 26 Final, July 12, 2001.

9 American Academy of Pediatrics, Committee on Nutrition: Clinical Testing of Infant Formulas with Respect to Nutritional Suitability for Term Infants. Elk Grove Village, American Academy of Pediatrics, 1998, pp 1-36.

10 Committee on Medical Aspects of Food and Nutrition Policy (COMA): Guidelines on the nutritional assessment of infant formulas. DHSS report No. 47, 1996.

11 Food and Drug Administration: Food Advisory Committee meeting on infant formula. www.fda.gov/ohrms/dockets/ac/02/roster/ 3852r1.pdf. 